Trivent Publishing

(C) The Authors, 2016

Available online at http://trivent-publishing.eu/

Engineering and Industry Series

Volume Power Systems, Energy Markets and Renewable Energy Sources in

South-Eastern Europe

\title{
The Integration of Applications for the Revitalization of the Hydro North Remote Control Centre on the Drava River in Croatia
}

\author{
Bruno Pavlović, ${ }^{1}$ Branko Horvat ${ }^{2}$ \\ ${ }^{1}$ Market and extended real-time applications, KONČAR - Power Plant and \\ Electric Traction Engineering Inc., Croatia, bruno.pavlovic@ koncar-ket.hr \\ ${ }^{2}$ Management assistance, KONČAR - Power Plant and Electric Traction Engineering \\ Inc., Croatia, branko.horvat@koncar-ket.hr
}

\begin{abstract}
Planning the optimal production schedule, the execution, and supervision for a hydropower system on the Drava River is highly important for the Croatian power system operation. The optimization is performed within the Production Centre North and its result is the generation of the Hydro North area schedule's power plants and power units. The main goal of the optimization is to minimize water usage while maximizing electrical energy production, taking into account the hydro energetic system's physical, technical, and operational constraints. The mixed integer linear programming method is used for optimization.
\end{abstract}

\section{Keywords}

Hydropower system; three hydropower plants on the same river; control centre; SCADA; short-term generation scheduling and optimization; various applications

This is an Open Access article distributed in accordance with the Creative Commons Attribution Non Commercial (CC-BY-NC-ND 4.0) license, which permits others to copy or share the article, provided original work is properly cited and that this is not done for commercial purposes. Users may not remix, transform, or build upon the material and may not distribute the modified material (http://creativecommons.org/licenses/by-nc/4.0/) 


\section{Introduction}

The production area of the hydropower system (HPS) in the northern part of Croatia (Hydro North; HN) consists of remote monitoring, a control centre (Control Centre North; CCN), and three hydropower plants (HPP) within the Drava River catchment in Croatia: HPP Varaždin, HPP Čakovec and HPP Dubrava. HPP Varaždin has a power capacity of $94 \mathrm{MW}$, while HPP Čakovec and Dubrava have a capacity of $76 \mathrm{MW}$ [1]. The following functions are conducted in the control centre: catchment supervision, production planning, operation, and control. The map of the system is shown in Fig. 1.

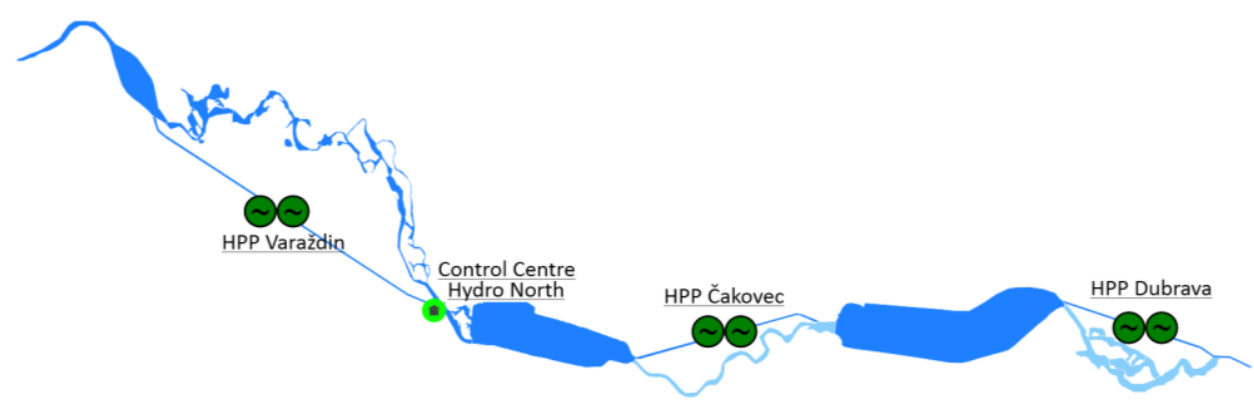

Fig. 1. Map of the Hydro North hydro power system

The revitalization of Hydro North started in late 2013 and was completed at the beginning of 2016 [2]. The main reasons for the revitalization were its lack of economical or technical justification for further system maintenance and questionable reliable operation in the future.

Apart from hardware replacement, the revitalization included the following: System Control and Data Acquisition (SCADA), short-term production planning, i.e., generation scheduling and optimization, automatic generation control, smart metering, voltage and reactive power supervision and control, data warehouse, and web applications. Some of these functions were already present in Hydro North, but some of them are new. The revitalization also included an upgrade of the telecommunication system and the adaptation of process control and information systems in the HPPs of Hydro North.

The upgraded system ensures the secure and reliable operation through the redundancy of critical functions on both the hardware and software level. The improvement of the business process and operation automation will increase profit from energy production as well as benefit from environment protection and flood control in Hydro North. With SCADA, there are also integrated 
commercial program packages such as: hydrology process simulator, optimization solver, as well as databases and a data warehouse.

The SCADA system is object-oriented as well as component and standard based, which enables future upgrades with new modules from various vendors. Communication with Programmable Logic Controllers (PLCs) in HPPs is done using an IEC 60870-5-104 communication protocol. Volt/Var supervision and regulation consists of a cascaded control algorithm with an outer loop in the centre and inner loop in PLCs in HPPs. An automatic generation control monitors an HPPs production and sends commands to their DCS's PLCs in order to maintain the plan.

A web portal offers on-line and off-line web-based reports for internal and external system users. Smart metering system is in charge of collecting, analysing, verifying, and managing data from meters in HPPs and it uses the processed data for creating reports and exporting them.

Generation scheduling and optimization application is used for the creation of short-term operation plans for one to seven days using discrete time intervals of 30 or 60 minutes. Optimization's main objective is not only to maximize operational efficiency but also to emphasize particular criteria. A Goal function can be modified through weight coefficients and penalty factors depending on the current role of the HPS. The roles are: planned production (execution of the schedules), run-of-the-river operation (inflow tracking), or flood protection by reservoir pre-empting as well as coordinated generating and spilling. There are appropriate databases for particular applications and one common archive database that integrates the data from all of the applications. In a data warehouse, specific data are collected and analysed.

Finally, the integration of the many internal and external applications into fully reliable and operating system must be emphasized. This system incorporated many algorithms and outputs that were designed, programmed, and implemented according to the Employer's needs.

It should be noted that a similar system had been implemented for Hydro South and the goal was to expand these solutions to other regional centres in Croatia. This paper provides an overview of the revitalized Hydro North from its structure to its use. The production planning, including generation scheduling and optimization, is discussed. Further, the mathematical modelling methodology is examined in greater detail. Finally, influence of the operation planning and generation control, as well as conditions making the hydropower process modelling difficult, are addressed. 


\section{Applications integration}

The scheme of application and database integration in the revitalized centre is shown in Fig. 2.

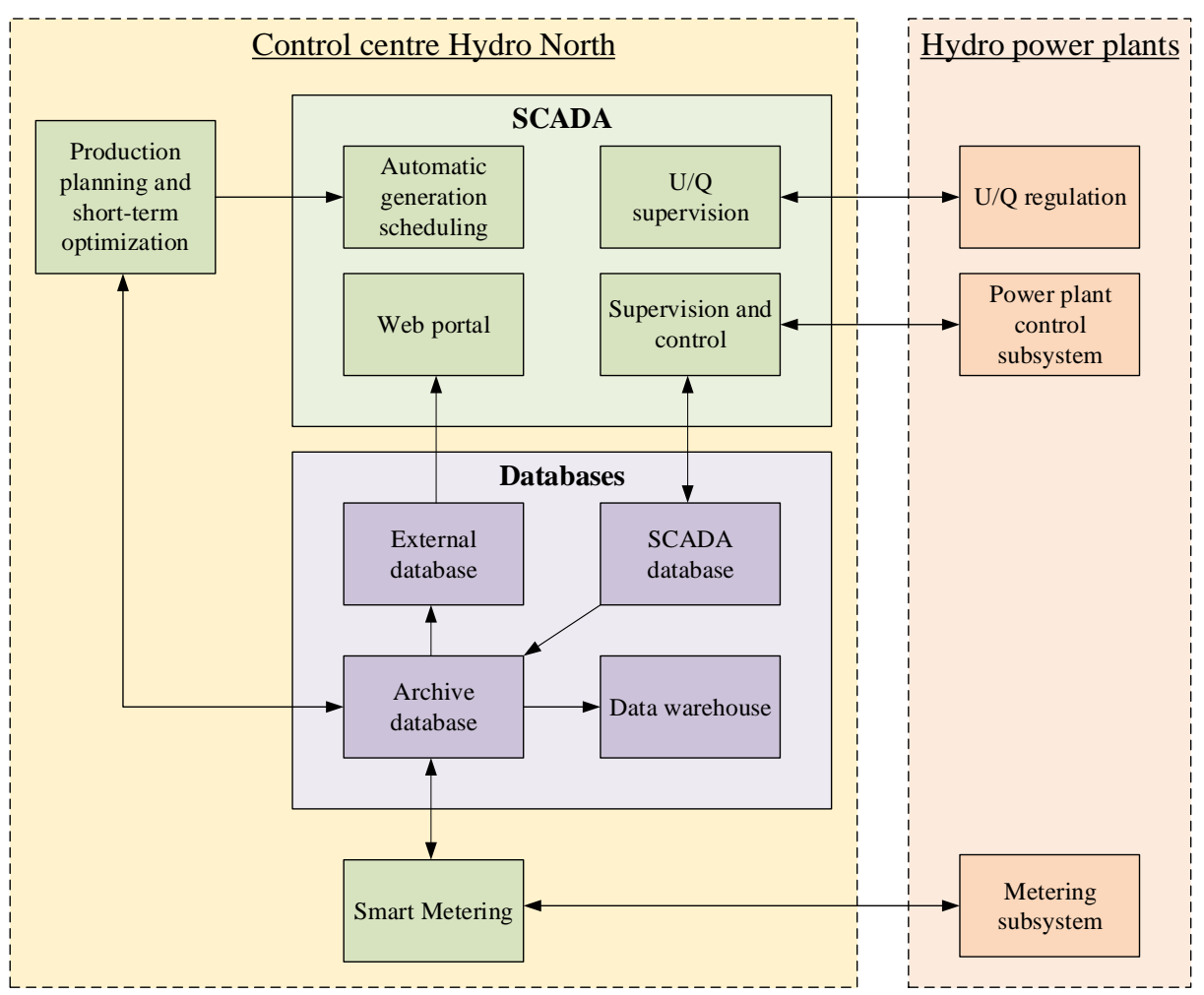

Fig. 2. Application integration in the revitalized $\mathrm{CCN}$

Most of the applications are tailor-made, although for some functions e.g. simulations in production planning, the short-term optimization algorithm, databases and data warehousing, commercial program packages are used. An overview of applications and databases used in $\mathrm{CCN}$ is given in Table. 1. 
Table 1. List of application software in the $\mathrm{CCN}$

\begin{tabular}{|c|c|c|}
\hline Application & Software/module & Manufacturer \\
\hline SCADA & PROZA NET & Končar \\
\hline \multirow[b]{2}{*}{$\begin{array}{l}\text { Short-term } \\
\text { generation } \\
\text { scheduling } \\
\text { and } \\
\text { optimization }\end{array}$} & CPLEX & IBM ILOG \\
\hline & $\begin{array}{l}\text { MIKE Hydro } \\
\text { Basin } 2014\end{array}$ & DHI \\
\hline $\begin{array}{l}\text { Automatic } \\
\text { generation } \\
\text { control }\end{array}$ & $\begin{array}{l}\text { PROZA NET } \\
\text { module Process } \\
\text { Controller }\end{array}$ & Končar \\
\hline \multirow{2}{*}{$\begin{array}{l}\text { Voltage and } \\
\text { reactive } \\
\text { power } \\
\text { control }\end{array}$} & PROZA NET & Končar \\
\hline & Control Builder & $\mathrm{ABB}$ \\
\hline \multirow{2}{*}{$\begin{array}{l}\text { Smart } \\
\text { metering }\end{array}$} & MARS & Končar \\
\hline & SEP2W & Iskraemeco \\
\hline \multirow{2}{*}{ Databases } & $\begin{array}{l}\text { Enterprise Edition } \\
12 \mathrm{c}\end{array}$ & Oracle \\
\hline & $\begin{array}{l}\text { SQL Server } \\
\text { Standard } 2012\end{array}$ & Microsoft \\
\hline $\begin{array}{l}\text { Data } \\
\text { warehouse }\end{array}$ & $\begin{array}{l}\text { Business } \\
\text { Intelligence } \\
\text { Standard Edition } \\
\text { One }\end{array}$ & Oracle \\
\hline \multirow[t]{2}{*}{ Web portal } & $\begin{array}{l}\text { Internet } \\
\text { Information } \\
\text { Services }\end{array}$ & Microsoft \\
\hline & Highstock & Highsoft \\
\hline
\end{tabular}

\section{The application for short-term generation scheduling and optimization - basic architecture}

The application for short-term generation scheduling and optimization is implemented in three-tier architecture as seen in Fig. 3. 


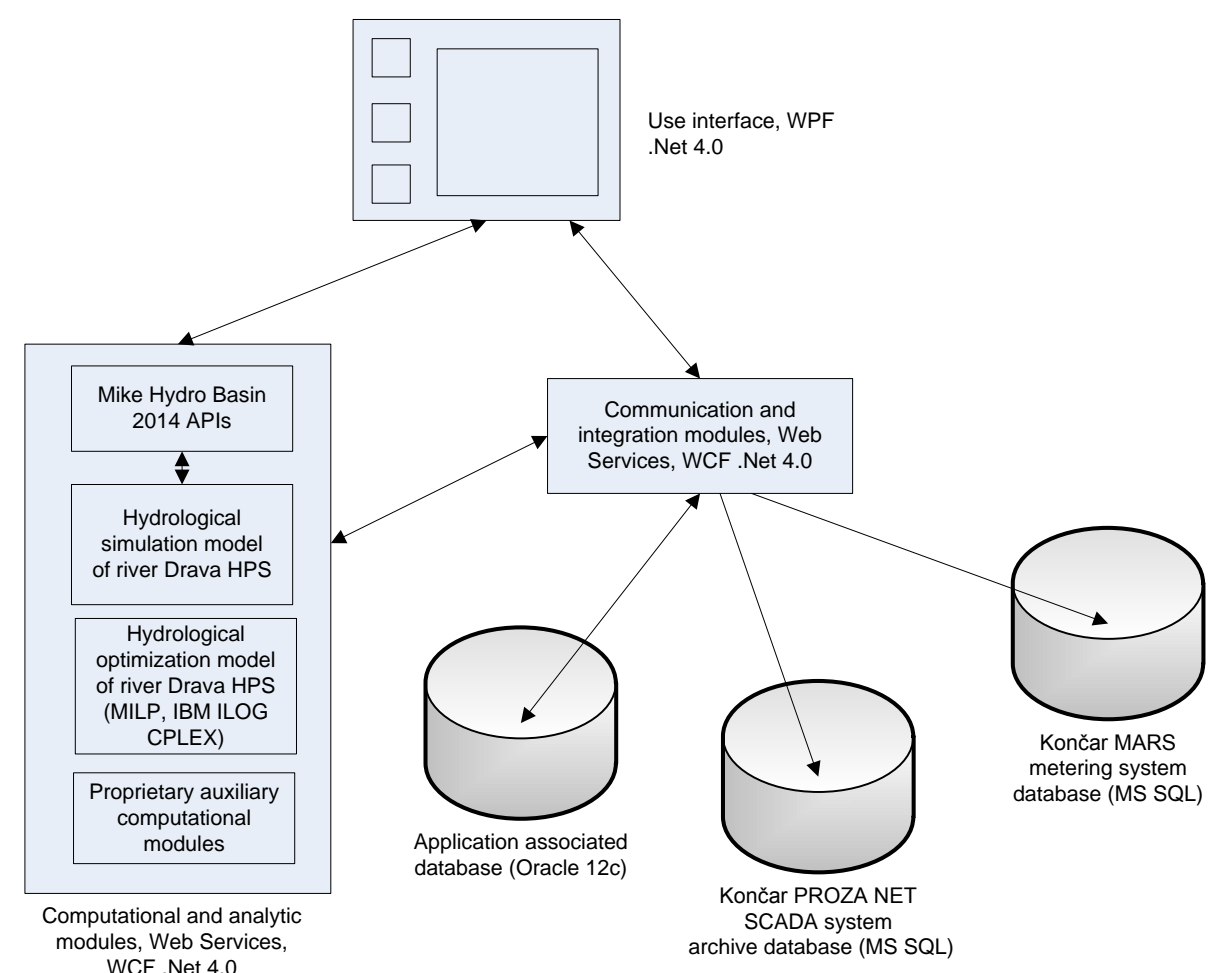

Fig. 3. Application architecture design

A presentation layer is implemented in Microsoft WPF (Windows Presentation Foundation), a modern presentation technology based on the .Net 4.0 development platform. The application user interface is pictured in Fig. 4.

The middle layer, or business logic, is implemented in Microsoft WCF (Windows Communication Foundation) Web Services technology also on the .Net 4.0 development platform. It encompasses a wide array of computational, analytic, communication, and integration functionalities. The computational part of the business logic bases the implementation of simulation scenarios on the DHI Mike Hydro Basin 2014 tool for hydrological modeling. This tool is used in defining the kinematic model for the Drava River HPS. Communication with model is done through Mike Hydro Basin 2014 APIs.

The communication and integration part of business logic model enables interaction of the application user interface with the application database. This part also enables interaction of the whole application with other components of the CCN system, e.g., with the Končar PROZA NET SCADA system in measurement data retrieval for the purpose of re-planning or plan fulfilment 
comparison as a part of the analytic function offered through the application. The persistence layer is implemented as an associated Oracle 12c database.

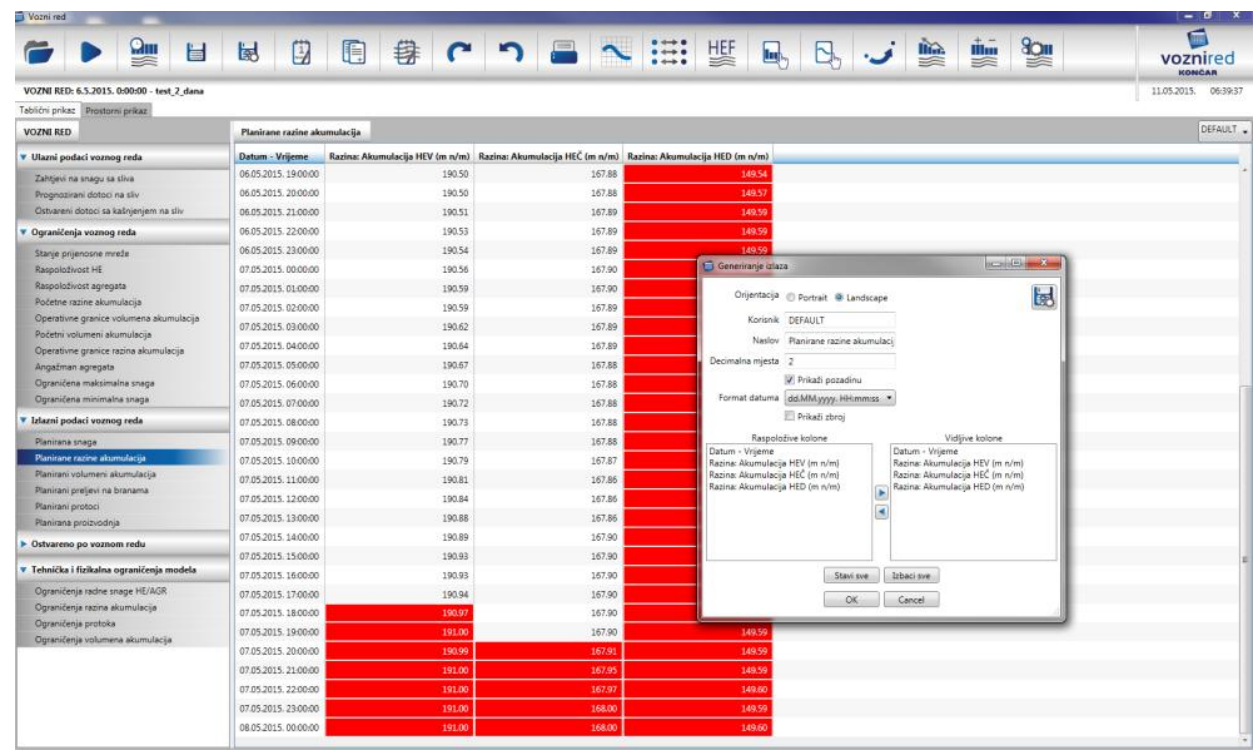

Fig. 4. Application user interface

The main computation module for short-term generation scheduling and optimization organizes input data in two groups: constraints and demands. Constraints encompass the availability and mandatory commitment of machines, reservoir water level, the operational boundaries of machines, etc. Demands data includes HPS hourly power total, starting reservoir water levels, total inflow, and other metrics.

The application also offers a few analytic tools for the graphical and tabular display and comparison of active plan components. In addition to this function, this application can generate statistical plan comparisons and reports. Fig. 5 shows an example of the module for the graphical and tabular display and comparison of plan components in action.

The application is comprised of a water simulation and energy balance model and uses the following computational modules for its calculations:

- hydropower planning,

- short-term generation schedule optimization,

- retrieval and processing of realization data,

- hourly average of HPP Formin turbine discharge computation,

- corrected Varaždin reservoir inflow calculation,

- plan fulfilment comparison, calculation of timeframe needed to reach a 
requested reservoir water level,

- calculation of reservoir water level reached within a set timeframe.

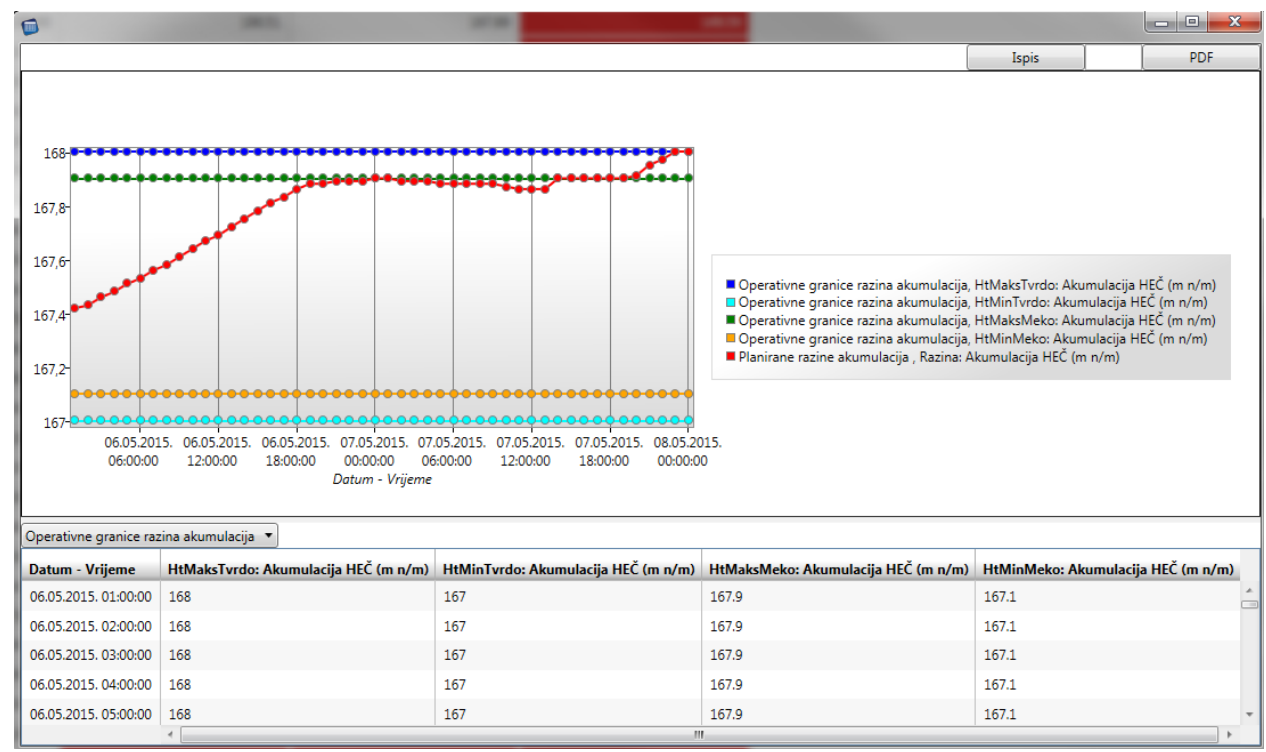

Fig. 5. Graphical and tabular comparison of active plan component

The last two auxiliary computational modules are specialized simulations that are a product of the interaction with the DHI Mike Hydro Basin 2014 software. It is similar to the way in which the main computational module handles simulation scenarios. The difference is in the focus on a certain object and its output whereas the main computational module deals with the whole model and all of its objects. Other auxiliary computational modules are fully proprietary.

The simulation outputs are as follows:

- $\quad$ planned power for machinery, HPP and HPS,

- planned reservoir water levels,

- planned reservoir volumes,

- $\quad$ planned spill from reservoir dams,

- $\quad$ planned flow in key points of HPS.

Many different operational situations can befall the Drava River HPS. Optimization has been conducted in such a way that maximum utility of available water resources and power production is achieved under any given conditions. The Drava River HPS work modes, for which the optimization model is accommodated, are: planned production (execution of schedules), runof-the-river operation (inflow tracking), and flood protection. The weight 
coefficients and penalty factors of the optimization function are automatically modified with the goal of achieving beneficial optimization results for a selected work mode.

Optimization scenarios in line with the three previously mentioned work modes are implemented through a mixed integer linear programming (MILP) approach. The basics of the algorithm conducting and solving the aforementioned MILP model for the Drava River HPS can be seen in Fig. 6. As a note, the solver used in the implementation of the optimization algorithms is IBM ILOG CPLEX.

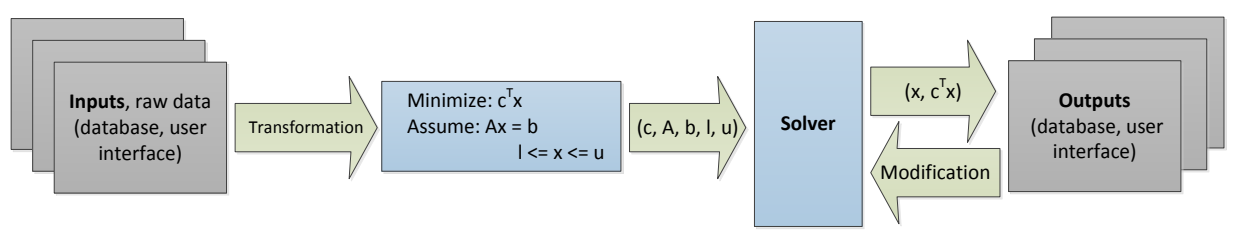

Fig. 6. Optimization algorithm execution

\section{Specifics of the HPS influencing the operation planning and generation control}

The Drava River HPS is operationally complex. The total installed power of HN amounts to $246 \mathrm{MW}$, which is a significant capacity in the Croatian electric power system (EPS). Nevertheless, the HPS receives slightly special treatment, e.g., allowing some freedom and independence in operation planning and decision making for real-time control in an effort to maintain system variables within an acceptable operational state.

Water volume in the reservoirs is the primary state variable of the HPS. Several factors are outlined in this set of variables: the quantity of "fuel in the warehouse", the level of electric power generation and efficiency, as well as the ability to accept a surplus of incoming water. The reservoirs of all three HPPs have a relatively small capacity, which increases the further downstream the HPP sits. The storage of the reservoir located furthest upstream at HPP Varaždin, with an active volume of $2.8 \mathrm{hm}^{3}$ is the smallest, which is unfavorable for the HPPs' cascade planning and operation. The other two reservoirs have significantly larger active volumes of $10.5 \mathrm{hm}^{3}$ (HPP Čakovec) and $16.6 \mathrm{hm}^{3}$ (HPP Dubrava).

The upstream HPPs in Slovenia track the daily consumption of their EPS, while also offering secondary control services to their Transmission System Operator (TSO). The consequence of that is a stochastic behavior of water 
inflow to HN HPS. A second, and even more unpleasant consequence, is a lack of synchronicity of water inflow with the daily load diagram shapes of the Croatian EPS because of significant water transport delays. The mean long-term annual average river inflow at the Croatian-Slovenian border is about $315 \mathrm{~m}^{3} / \mathrm{s}$ with an installed discharge of $500 \mathrm{~m}^{3} / \mathrm{s}$ from the HPPs. The maximum inflow was recorded three years ago and reached $3300 \mathrm{~m}^{3} / \mathrm{s}$, [1].

HN HPS does not participate in secondary control due to restrictions on changes of turbine discharge rates. These restrictions originate from stability demands imposed on the hydraulic structures of tail-water diversion channels. For years, the HPS has offered tertiary control and balancing services to the TSO in accordance with its capabilities and operational status. Of course, the tertiary reserve has to be planned not only in order to conserve the capacities but, to take into account the design restrictions on the start-up and shutdown times of installed bulb turbines in HPP Čakovec and HPP Dubrava. The HPS also supplies system support in the event of contingencies. This is often called maintaining the system "security".

The demanded hourly total for HPS electric power, agreed upon with the electricity trading company, is the primary goal for the operation planning optimization criteria function. Reservoir water levels must be kept inside their prescribed limit ranges, though. Occasionally, there is need for a change in the operation for the remainder of the planning period due to changes in the hourly total demand dictated by the upper levels of the organization or from unexpected changes in inflow. In some cases, there are requests for planned variations of reservoir water volumes (and levels) outside of the normal ranges to prepare them for increased inflows or to enable preventive, or periodic maintenance of the dam spillway equipment or a survey of reservoir dikes.

\section{Facts making the hydropower process modelling of the HPS difficult}

A production planning application is used for the creation of operation plans for periods of one to seven days using discrete time intervals of 30 or 60 minutes. Intra-day scheduling is also supported in the optimization subsystem. Planning optimal production for HPSs of the Drava River, as well as execution and supervision, is of high importance for the Croatian power system operation.

Optimization is performed within $\mathrm{CCN}$ and it results in generation scheduling for power plants and power units of the $\mathrm{HN}$ area. The primary goal of optimization is to minimize water usage while maximizing electrical energy production, done while taking into account HPS's physical, technical, and 
operational constraints. An optimization's goal function can be modified through weight coefficients and penalty factors for various scenarios such as planned production, inflow tracking, or flood protection, according to the role of $\mathrm{HN}$ HPS.

The goal function components incorporate HPS power balance during discrete time intervals as along with the economic production unit commitment and the load distribution. Additional members of the function consist of: reaching generation target, penalizing the reservoirs' water level deviations, and reducing start-up/shutdown costs. A Mixed Integer Linear Programing (MILP) method is used for optimization calculation [3]. In this, the output power and binary production unit commitment are both decision (optimization) variables for each HPP and for every discrete time interval.

The main difficulty in the optimization calculation is related to the nonlinear relationships among the output of generated power, the water discharge, and the net hydraulic head of the corresponding HPP. Therefore, the characteristics of reservoirs, diversion channels, and generating units are approximated by piecewise linear separable functions [4].

The scheme of the HPS's mathematical model is numerically demanding due to complex hydraulic topology and various interdependences. The HN HPS consists of three reservoirs, each with long headrace and tail-water diversion channels and the HPPs' powerhouses in between. There are also old river bed running parallel to these features (Fig. 1).

It is well known that optimization problem constraints represent a mathematical model of the process. The constraints include equalities and inequalities. The equalities relate to water conservation, supply and demand power balances, generating units' and channels' characteristics, as well as the dependencies on reservoir water volumes. Inequalities include physical, technical, and dispatcher constraints and bounds, as well as operational constraints and bounds $\{0,1\}$ on integer (binary) decision variables of generating unit commitment, start-up and shutdown. The main aim of the optimization is to maximize the operational efficiency, i.e., to minimize the amount of water used. Additional aspects are: attaining the generation target, dealing with reservoir level variations, and reducing start-up/shutdown costs. Therefore, the goal function has the form given in Eq. 1. By careful tuning and differentiation of the weighting factors, penalty factors, and costs in the goal function, the emphasis on a particular criteria is achieved. 


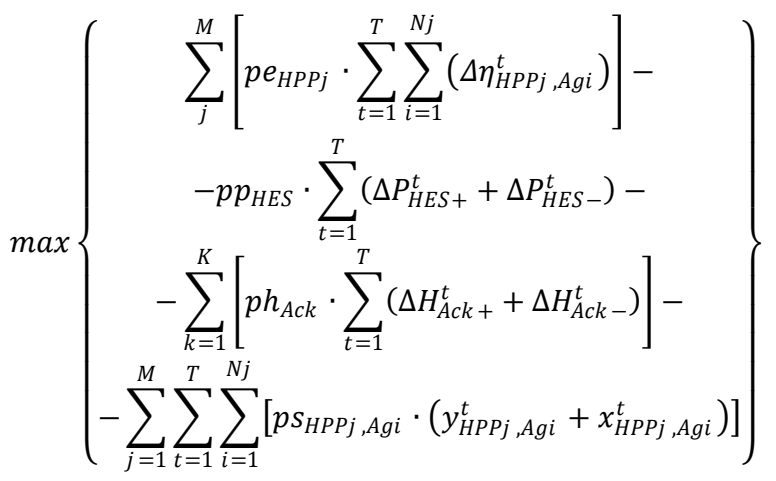

Where: $M$ - total number of HPPs, $N j$ - total number of generating units in HPP $j, T$ - total number of discrete time intervals, $K$ - total number of reservoirs, $p e_{H P P j}$ - generating unit efficiency weighting factor in HPP $j, p p_{H E S}$ - penalty factor for Drava HPS target power, $p h_{A c k}-$ penalty factor for reservoir $k$ water level deviation, $p s_{H P P j_{1} A g i}-$ start-up/shutdown costs for generating unit $i$ in HPP $j, \triangle \eta_{H P P j, A g i}^{t}-$ deviation of generating unit $i$ efficiency from minimum in $\operatorname{HPP} j$, $\triangle P_{\text {HES }}^{t}$ and $\Delta P_{\text {HES }}^{t}$ - positive and negative deviations of total Drava HPS generation, $\Delta H_{A c k+}^{t}$ and $\Delta H_{A c k-}^{t}-$ positive and negative deviations of water level in reservoir $k, y_{H P P D_{j} A g i}^{t}-$ start-up decision variable $\{0,1\}$ of generating unit $i$ in $\operatorname{HPP} j, x_{H P P j, A g i}^{t}-$ shutdown decision variable $\{0,1\}$ of generating unit $i$ in HPP $j$.

There are more modelling difficulties caused by the obvious complexity of the conditions in an HPS such as: head variations at HPPs and nonlinear functions, e.g., turbine discharge, head loss in headrace channel, water level in tail-water channel, and water transport delays.

1) Head variations at HPPs have an influence on output power and water consumption, which cannot be disregarded. The variations of water level in the tail-water channels cannot be neglected and the friction head losses in the headrace channels are noticeable. As a result, in the models simulating a units' water consumption and the efficiency characteristics of the HPPs as well as head loss and tail-water level characteristics of the diversion channels, there is some multiplicity. Because of that, the operation planning for such HPPs is much more complex than for those with a constant head. Geometrically, multiple characteristics go over to a surface on which turbine discharge and efficiency, head loss or tail-water level, are functions of two variables, e.g., output power and hydraulic head for turbines.

2) The functions referred to here are nonlinear. For example, in the case of a constant head for the units of an HPP, the nonlinear function, e.g., turbine 
discharge, of a single variable, e.g., output power, may be approximated by a piecewise linear separable function [4]. But there is also a method which, in a similar way, approximates a function of two variables [5]. This method makes approximate nonlinear programming problem solving possible where various constraints (in this case, multiple characteristics) are expressed as a sum of the nonlinear functions in two variables. The drawback of this method is it generates numerous integer (binary) decision variables with integrality constraints, which makes the optimization more difficult and time consuming. The solution to this problem may be in the concept of special ordered sets [6].

3) The head loss caused by friction in the headrace diversion channel depends not only on the flow but also on the water level in the reservoir. The lower the water level, the bigger the head loss is because of the increased water velocity in the channel. The dependence is nonlinear and has to be modelled as a function of two variables [7].

4) The water level in the tail-water diversion channel depends not only on the turbine discharge of the HPP but two other factors: the water level in the downstream reservoir and the backwater from the river caused by the increased flow spilled at the dam of the appertaining reservoir. The dependences are markedly nonlinear and have to be modelled as a function of two variables.

5) Large and duration diverse water transport delays in various watercourses of the HPS (reservoirs, diversion channels, and old river bed), spread the variables (flows) of the model in time. These variables, together with water volumes in the reservoirs, make the memory of the system. The complex interdependence between these real variables points out the time inseparability of the HPS and strongly influences the optimization calculations.

\section{Example}

In Fig. 7, the outputs of generation schedule optimization in line with the planned production (execution of the schedule) work mode are compared to the realization in a given time period. The selected output time series for comparison are HPS power production total and water levels for one particular reservoir.

As presented in the figure, total realized HPS power production and reservoir water levels closely follow the plan in shape and value. This confirms accordance of the HPS optimization model behavior with real-world HPS object relations and dependencies.

\section{Conclusion}


The main point that has to be emphasized is the integration of the many and complex internal and external applications into a fully reliable and operating system. A system in which many algorithms and outputs were designed, programmed, and implemented according to the expert knowledge and experienced work staff.

It should be noted that a similar system had already been implemented in Croatia for Hydro South [8]. The aim is to expand these solutions to other regional control centers in Croatia. Ultimately, all of the regional centers will be into one central monitoring system.

The applications for the various subsystems in $\mathrm{CCN}$ do not only use tailormade solutions from the commercial market. Many algorithms and outputs were designed, programmed, and implemented according to the specific needs of the HPS and the Croatian EPS.

\section{References}

[1] Miljenko Brezovec, Goran Zrinski, Željko Štefan, Operation of cascaded hydro system in flood situation (Proceedings, Hydro 2013)

[2] HEP, Tender documents for the Revitalization of remote monitoring and control centre (KL Varaždin), (in Croatian) (HEP Proizvodnja d.o.o., Production Area Hydro Power Plants North -Varaždin, Croatia, 2013)

[3] IBM ILOG, User's manual for CPLEX V12.2 (IBM Corp., 2010)

[4] H. Paul Williams, Model building in mathematical programming, 4th edition (J. Wiley and sons, 1999)

[5] Djangir A. Babayev, Piece-wise linear approximation of functions of two variables (Journal of Heuristics 2, 1997), 313-320.

[6] Evelyn Martin Lansdowne Beale, J. A. Tomlin, Special facilities in a general mathematical programming system for non-convex problems using ordered sets of variables, in J. Lawrence Ed. (Proceedings of the $5^{\text {th }}$ International Conference on Operations Research, Tavistock, London, 1969

[7] V. T. Chow, Open channel Hydraulics (McGraw-Hill, 1988)

[8] Branko Horvat, Ante Martinić, Mate Dabro, Tonći Blažević, Cetina river catchment control centre: Combining commercial and tailor-made solutions (Hydropower \& Dams, Issue 6, 2012) 


\section{Legend:}

Fig. 7. Realization example of a production plan

Planned production: blue

Planned reservoir levels: blue
Realized production: cyan

Realized reservoir levels: cyan
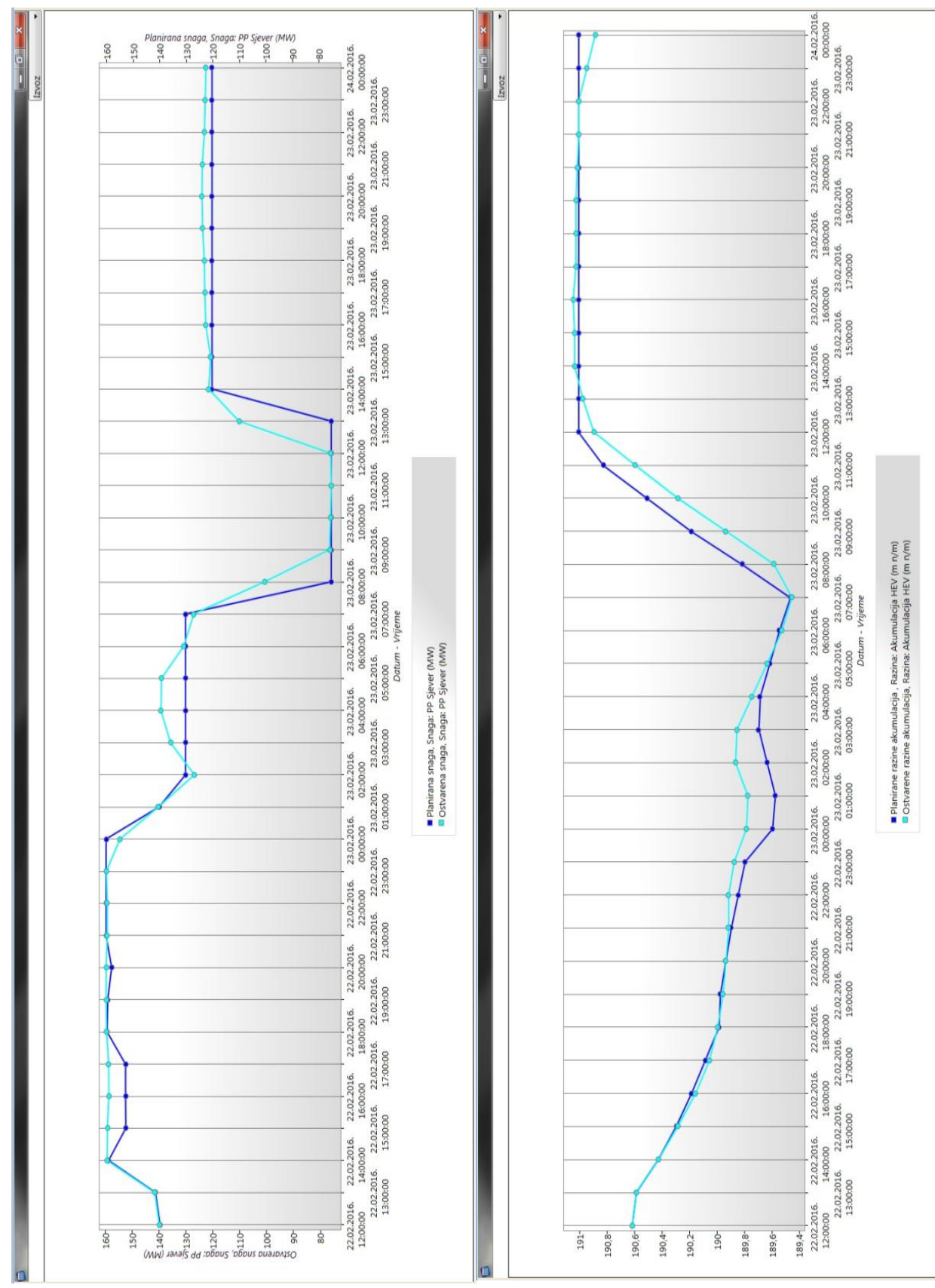